\title{
Self-absorption Correction Factors: Applying A Simplified Method to Analysis of Lead-210 in Different Environment Samples by Direct Counting of Low-energy Using HPGe Detector
}

\author{
Jawaher AL-TUWEITY ${ }^{1 *}$, Hassan KAMLEH $^{2}$, M. Said AL-MASRI ${ }^{3}$, A. Wael DOUBAL ${ }^{4}$, El Mahjoub CHAKIR ${ }^{l}$ \\ ${ }^{1}$ LPMS, Physics Department, University of Ibn Tofail UIT, P. O. Box 133, Kenitra, Morocco \\ ${ }^{2}$ Physics Department, Damascus University, Damascus, Syria \\ ${ }^{3}$ Department of Protection and Safety, Atomic Energy Commission of Syria AECS, Damascus, Syria \\ ${ }^{4}$ Basic Science Department, Faculty of Electrical and Mechanical Engineering, Damascus University, Syria
}

\begin{abstract}
This study aimed to determine the self-absorption correction factors of lead-210 $\left({ }^{210} \mathrm{~Pb}\right)$ in various Syrian environment samples. Seven sediments, five soils, and four plant samples were analysed by Gamma Spectroscopy using simple and direct analysis method called Cutshall. The method is based on measuring the penetration of gamma which emitted from a standard source, prepared in the laboratory by deposition of QCYB40 Standard Solution on stainless steel disk. The source was placed on top of the studied sample and the reference air sample during the measurement. The purpose was to study the self-absorption inside each sample by calculation of its self-absorption factors without knowing its chemical composition. The self-absorption correction results for the sediment samples SE3, SE6 and SE8 ranged between $36 \%$ and $45 \%$, and $34 \%$ to $42 \%$ for the soil samples S5 and S1, respectively. Also, for the four plant samples, it recorded variance range from $4 \%$ to $18 \%$. This is due to the difference in the density of the G4 sample, which appeared to be very low. However, the self-absorption correction factors CF were set for the different environmental samples, and the results show that the density factor of the sample is not the only influent factor in the CF values for low energies measurement, the sample chemical composition (sample matrix) is also more effective in addition to the samples' particle sizes.
\end{abstract}

\section{Introduction}

Radioactive elements uranium and thorium, like most chemical elements, are formed in stars and comprise a small amount of the material that formed in the earth naturally. The radioactive isotopes uranium-238 $\left({ }^{238} \mathrm{U}\right)$ and thorium-232 $\left({ }^{232} \mathrm{Th}\right)$ have decay times (half-lives) which are comparable with, or larger than, the age of the earth, so they have always been present in the earth's crust and within the tissues of all living species [1].

Environmental monitoring and analysis of the isotopes' radioactivity concentration in different environment samples is essential to protecting public and environment from any radioactivity pollution, radiometric anomalies investigation, and also for studying the transportation of radioactive and dating. Lead-210 $\left({ }^{210} \mathrm{~Pb}\right)$ is a radioactive isotope (22.3 years) produced as a result of the ${ }^{238} \mathrm{U}$ chain decay, or radium $\left({ }^{226} \mathrm{Ra}\right.$ ) chain. ${ }^{210} \mathrm{~Pb}$ is called radium $\mathrm{D}$, and it is the longest-lived isotope between radioactive lead and radon daughters. ${ }^{210} \mathrm{~Pb}_{82}$ decay into its daughter ${ }_{83}{ }^{210} \mathrm{Bi}$ or what is called radium $\mathrm{E}$ (half-life 5.013 days) which emit beta $\beta$ particles with two different energies $15 \mathrm{keV}$ and $61 \mathrm{keV}$ with emission rates of $81 \%$ and $19 \%$, respectively. It emits gamma $\gamma$ radiation with an energy emission of $46.5 \mathrm{keV}$ (kiloelectron volt) and an emission potential of $4.26 \%$. ${ }^{210} \mathrm{Bi}$ decays in a cycle to polonium${ }^{210} \mathrm{Po}_{84}$, or what is called radium $\mathrm{F}$ (half-life 138.378 days), with approximately $100 \%$ of $\beta$ with energy of
$1161 \mathrm{keV}$, and $0.00013 \%$ of Bismuth is decay to Thallium ${ }_{81}^{206} \mathrm{Ti}$ with $\alpha$ emitted. The ${ }^{210} \mathrm{Po}$ decay with $\alpha$ emitted and two different energies, the first is $5.3 \mathrm{MeV}(99.999 \%)$, the second energy is $4.5 \mathrm{MeV}(0.001 \%)$, to reach the stable isotope ${ }^{206} \mathrm{~Pb}$ (Figure 1). ${ }^{210} \mathrm{~Pb}$ is concentrated in sediments of lakes, rivers, and continental and oceanic water [2], [3]. Its concentration in groundwater reaches $7 \mathrm{~Bq} / \mathrm{L}$. It also increases in some plant leaf such as lettuce and spinach, where it can reach $6 \mathrm{~Bq} / \mathrm{kg}$ of fresh weight. Eating $200 \mathrm{~g}$ of the plant daily leads to an internal dose of $55 \mu \mathrm{Sv}$ per year [2]. ${ }^{210} \mathrm{~Pb}$ is not considered a radiation hazard for human health by itself, but by its daughters' ${ }^{210} \mathrm{Bi}$ and ${ }^{210} \mathrm{Po}$ and to its chemical toxicity [2].

So, most the radiation dose caused by it is daughters because of its lower energy of $\beta$ particles $(61 \mathrm{keV}$ and $15 \mathrm{keV})$, also $\gamma$ emits $(46.5 \mathrm{keV})$ and the lower emission ratio of $\alpha$-particles.

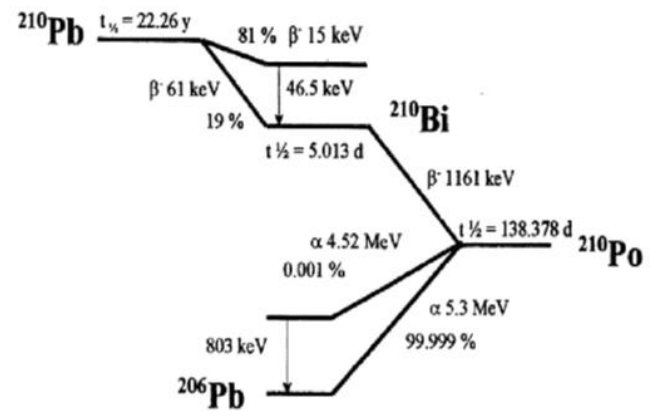

Fig. 1. ${ }^{210} \mathrm{~Pb}$ and its daughters ${ }^{210} \mathrm{Bi}$ and ${ }^{210} \mathrm{Po}$ decay [3]

*Corresponding author: jaltuweity@gmail.com 
There are different techniques used to determine the selfabsorption correction factors [5] [6] [7]. Since 1983, Cutshall developed an experimental method to determining self-absorption correction factors for low gamma-radiation energies [4]. He assigned the ${ }^{210} \mathrm{~Pb}$ (46.54 keV) germanium detector (with a beryllium window used for low gamma radiation) to measure the transmittance of gamma rays through sediment samples and by placing the ${ }^{210} \mathrm{~Pb}$ source on top of the sample while collecting the spectrum, with the same positioning of the source relative to the sample and the detector surface. This method is called the Cutshall method or the permeability method, and it is the method used in this work.

\section{Materials and method}

\subsection{Cutshall Method}

Cutshall method depends on the penetration of gamma rays through the sample which we need to set its selfabsorption correction factor. Self-absorption correction has many parameters such as source intensity, the isotope to be assigned and its energy (high or low), sample thickness, density, chemical composition and the weight ratios of each compound or element, the organic content, the humidity coefficient, the homogeneity of the sample and others. Also, there are other parameters that depend on detector specifications, type, dimensions, and source location to the sample and detector during the measurement and spectrum collection. This method requires a radioactive source that emits energy close or similar to the isotope energy. Also, it is required activity of the source higher the studied sample, meaning that the activity of the sample has to be negligible when compared to the source activity. Since the isotope to be determined in this study is ${ }^{210} \mathrm{~Pb}$, this required preparing the source of ${ }^{210} \mathrm{~Pb}$, which is placed at the top of the studied sample during the collection of the spectrum and the count value (Count) is recorded under the peak of ${ }^{210} \mathrm{~Pb}$ and the collection time per (Sec). The count rate (Count Sec-1, CPS) is obtained by dividing the count by the collection time. Consider $I_{S}$ represents the count rate for the studied sample with the source and $I_{\text {air }}$ is the count rate for the reference air (empty petri can). Table 1 shows the counting results for the reference air sample. If we consider the attenuation of air is equal to zero, we obtain the correction factor for self-absorption experimentally as the following formula:

$$
F_{\text {air }, \operatorname{Exp}}^{S}=\frac{\operatorname{Ln}\left(\frac{I_{S}}{I_{\text {air }}}\right)}{\left(\frac{I_{S}}{I_{\text {air }}}\right)-1}
$$

The self-absorption correction factors shown in Tables 2 , 3 , and 4 were calculated using formula 1 . The good thing with the formula, is it does not need to know the standard source activity, and it is sufficient that its activity is higher than the expected activity of the sample. In addition, its results are quick and fairly accurate. By multiplying the measured sample activity by the self-absorption correction factor, we obtain the corrected activity of the sample. The correction ratio is calculated from the following formula [8]:

$$
C_{\text {air }, \text { Exp. }}^{s}=\left(1-\frac{1}{F_{\text {air }, \text { Exp. }}^{S}}\right) * 100 \%
$$

$F_{\text {air,Exp. }}^{\text {S }}$ represents the experimentally calculated selfabsorption correction factor Exp., for the sample, and for the air. $C_{\text {air,Exp. }}^{S}$ : Represents the correction ratio for selfabsorption correction factors experimentally Exp., for sample s, and for air. This formula was used to calculate the self-absorption correction ratio Tables 2, 3, and 4 .

\subsection{Sample preparation}

Samples (sediment, soil, plant) were prepared and filled in a Petri dish, with a thickness of $1.2 \mathrm{~cm}$, and volume of $24.73 \mathrm{~cm}^{3}$.

\subsection{Spectrum collection and analysis}

The spectrum was collected by a HpGe Spectroscopy system. The spectrum for each sample was collected during $500 \mathrm{sec}$ with the standard ${ }^{210} \mathrm{~Pb}$ on top of the sample. The previous step was repeated for the different sample's sediment, soil, plant and air (with empty petri dish). $A{ }^{210} \mathrm{~Pb}$ peak was recorded for each measurement separately, taking into account the position of the standard source and the sample to each other also, to detector surface center which have to be the same position.

Table 1. shows the measured permeability results for the reference air sample of the detector (its thickness is $1.2 \mathrm{~cm}$ ).

\begin{tabular}{|c|c|c|c|}
\hline Sample & Density $\mathbf{g} / \mathbf{c m}^{3}$ & Sec & COUNT \\
\hline Air & $1.2923 * 10^{-3}$ & 500 & 2880 \\
\hline
\end{tabular}

Table 2. Correction Factors for sediment

\begin{tabular}{|c|c|c|c|}
\hline $\begin{array}{c}\text { Sample } \\
\text { ID }\end{array}$ & $\mathbf{g} / \mathbf{c m}^{\mathbf{3}}$ & $\mathbf{F}_{\text {self-Absorption }}$ & $\mathbf{C}_{\text {self- Absorption }} \boldsymbol{\%}$ \\
\hline SE3 & 1.85 & 1.82 & 45 \\
\hline SE4 & 1.41 & 1.52 & 34 \\
\hline SE5 & 1.57 & 1.63 & 39 \\
\hline SE6 & 1.32 & 1.56 & 36 \\
\hline SE7 & 1.44 & 1.60 & 38 \\
\hline SE8 & 1.51 & 1.55 & 36 \\
\hline SE9 & 1.52 & 1.76 & 43 \\
\hline
\end{tabular}

Table 3. Correction Factors for soil samples

\begin{tabular}{|c|c|c|c|}
\hline Sample ID. & $\mathbf{g} / \mathbf{c m}^{\mathbf{3}}$ & Fself-Absorption & Cself- Absorption \% \\
\hline S1 & 1.68 & 1.74 & 42 \\
\hline S2 & 1.65 & 1.71 & 41 \\
\hline S3 & 1.58 & 1.69 & 41 \\
\hline S4 & 1.52 & 1.67 & 40 \\
\hline S5 & 1.50 & 1.52 & 34 \\
\hline
\end{tabular}

Table 4. Correction Factors for plant samples

\begin{tabular}{|c|c|c|c|}
\hline Sample ID. & $\mathbf{g} / \mathbf{c m}^{\mathbf{3}}$ & $\mathbf{F}_{\text {self-Absorption }}$ & $\mathbf{C}_{\text {self- Absorption }} \mathbf{\%}$ \\
\hline G1 & 0.75 & 1.17 & 14 \\
\hline G2 & 0.78 & 1.12 & 11 \\
\hline G3 & 0.79 & 1.22 & 18 \\
\hline G4 & 0.30 & 1.05 & 4 \\
\hline
\end{tabular}




\section{Results and Discussion}

Tables 2 and 3 show that the self-absorption correction ratio ranged between $45 \%$ and $36 \%$ for the SE3, SE6 and SE8 sediment samples while the correction ratio was less for S5 and S1 soil samples also ranged between 34\% and $42 \%$, respectively. It is also a clear relation with most samples' densities, the samples with higher density recording a higher correction of self-absorption, and opposite for the samples with low density values (Figures 2 and 3$)$.

The SE4, SE8 and SE9 sediment samples were noted variations in CF values in opposite to the soil's samples except the S4. This variation is due to the different particle sizes in these samples itself and sample matrix.

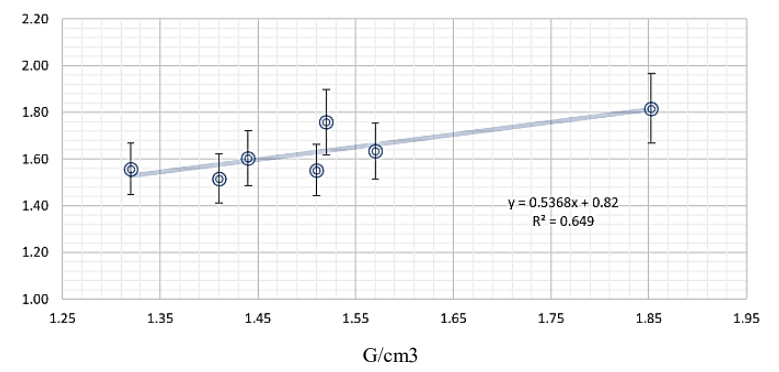

Fig. 2. Correction factors $C F$ with sediment sample density

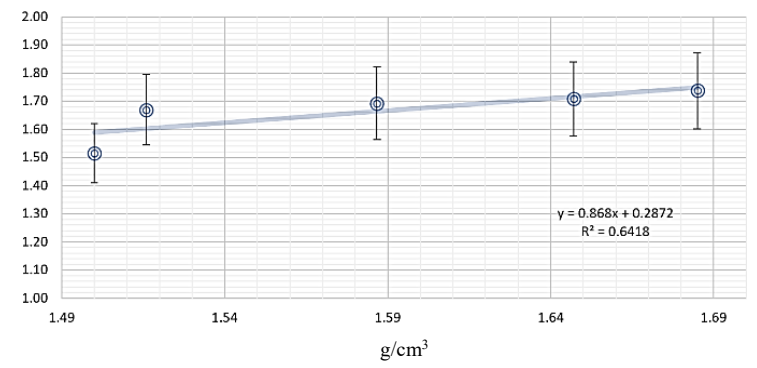

Fig. 3. Correction factors CF with soil samples density

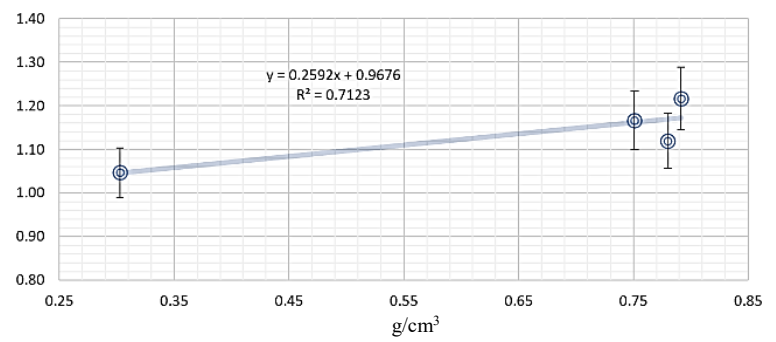

Fig. 4. Correction factors $\mathrm{CF}$ with plant samples density

Table 4 shows the self-absorption correction ratios of the four plant samples. The results have a variance range from $4 \%$ to $18 \%$. A major difference was observed between the sample densities in comparison with the rest of the plant samples, like sample G4 that has very low density values. Also, the G2 sample correction result did not match the results of the rest of the plant samples in harmony between the correction ratio and the sample density (Figure 4). This may be attributed experimentally to the difficulty in determining the density of plant samples because of their difference in physical properties and in the particle size even after grinding.

\section{Conclusions}

The self-absorption correction factors $\mathrm{CF}$ of ${ }^{210} \mathrm{~Pb}$ were set for the different environmental samples using Cutshall's method. The results show the density factor is not the only influent factor in the CF values for low energy measurement, the sample chemical composition (sample matrix) is also more effective in addition to the samples' particle sizes. The difference in particle size for the sediment and soil samples was an effective factor in calculation of the appearance density of the samples too even after sample grinding.

\section{Acknowledgments}

I would like to express my very great appreciation to Pr. Ibrahim Othman - Director of the Atomic Energy Commission of Syria AECS -Department of Protection and Safety - Damascus, Syria for his gracious and facilitation of our research work and encouragement on the accuracy of its completion.

\section{References}

1. S. Long, S. Sdraulig, B. Tate, P. Martin, Australian Radiation Protection and Nuclear Safety Agency, Technical Report No. 161, (2012)

2. Othman Ibrahim, M. S. AL-Masri, Syrian Atomic Energy Commission - Damascus, 2010

3. M. F. L'Annunziata, Handbook of radioactivity analysis. San Diego, CA: Academic Press. ISBN: 012-436603-1, (1998)

4. N. Cutshall, I. L. Larsen, C. R. Olsen, Nucl. Instr. and Meth. 206, 309-312, (1983)

5. J. Al-Tuweity, H. Kamleh, M. S. Al-Masri, A.W. Doubal, El. M. Chakir, E3S Web of Conferences, 234, 00051 (2021)

6. C. A. McMahon, J. Fegan. App. Rad. Isot. 60, 571577, (2004)

7. J. Al-Tuweity, H. Kamleh, M. S. Al-Masri, A.W. Doubal, El. M. Chakir, IRPA15 (2021)

8. AL-Aboud Hussain, Al-Gharib Iyad, Geology Department - Faculty of Science - Damascus University - Syria, 28-29 (2009) 